\title{
Aplicação de elemento de game design sociointerativo em simulações de código aberto do projeto PhET
}

\author{
Rafael João Ribeiro ${ }^{1}$, Sani de Carvalho Rutz da Silva ${ }^{2}$ \\ ${ }^{1}$ Campus Telêmaco Borba - Instituto Federal do Paraná (IFPR). Rodovia PR 160, Km \\ 19,5 - CEP 84269-090 - Telêmaco Borba - PR- Brasil. \\ ${ }^{2}$ Programa de Pós-Graduação em Ensino de Ciência e Tecnologia - Universidade \\ Tecnológica Federal do Paraná (UTFPR). Av. Monteiro Lobato, s/n - CEP 84016-210 - \\ Ponta Grossa - PR - Brasil. \\ \{rafael.ribeiro@ifpr.edu.br, sani@utfpr.edu.br\}
}

\begin{abstract}
The objective of this work was to evaluate the effects of the game design applied in interactive simulations of the PhET project, in the motivation of the students to spontaneously access this resource in situations outside the school context. The research methodology involved an experimental design with 75 students in the first year of higher education in three experimental class. An increase in students' spontaneous access to the simulations after the application of social interactive game design element was observed. In this case, the design element was the addition of an online highscore for recording scores obtained by the students in a modified simulation of the PhET project.
\end{abstract}

Resumo. O objetivo deste trabalho foi avaliar os efeitos da aplicação de game design nas simulações interativas do projeto PhET tendo em vista a motivação dos estudantes em acessarem, espontaneamente, esse recurso em situações fora do contexto escolar. A metodologia desta pesquisa envolveu um delineamento experimental com 75 alunos do $1^{\circ}$ ano do Ensino Médio Profissionalizante em três aulas experimentais. Observou-se um aumento no acesso espontâneo dos estudantes às simulações após a aplicação de elemento de game design sociointerativo, neste caso, com a adição de um placar geral para o registro online das pontuações obtidas pelos estudantes em uma simulação adaptada do projeto PhET.

\section{Introdução}

O projeto PhET, desenvolvido na Universidade do Colorado, disponibiliza 133 simulações interativas distribuídas livremente no portal $\mathrm{PhET}^{1}$, em até 36 idiomas, com

\footnotetext{
${ }^{1}$ PhET: Physics Education Technology. Disponível em: <https://phet.colorado.edu/>. Acessado em: 07 de fevereiro de 2016.
} 
conteúdos de Física, Química, Matemática e Biologia. Perkins et al. (2006), pesquisadores do grupo PhET, apresentam e discutem o método elaborado para a produção das simulações, que prioriza o engajamento e a melhoria da aprendizagem dos estudantes.

O sucesso do projeto PhET foi analisado por Khatri et al., (2014), que publicaram um estudo de caso para investigar questões sobre o desenvolvimento das simulações e compreender o motivo do sucesso desse recurso de ensino. Para a coleta de dados, os autores incluíram entrevistas com os profissionais fundadores do projeto, publicações sobre o processo de desenvolvimento das simulações, artigos em jornais e documentos publicados pelo grupo $\mathrm{PhET}$, ao longo dos anos desde a sua criação.

Após a análise dos dados, Khatri et al. (2014) destacaram três pontos-chave para o sucesso do projeto PhET. Primeiro, o grupo PhET passou por uma fase experimental antes de definir exatamente como seria sua inovação. No início, o grupo investiu em um período de validação dos conceitos e refinamento das ideias, até, finalmente, expandir para uma fase em grande escala. $\mathrm{O}$ segundo ponto-chave do projeto PhET foram as parcerias. O terceiro ponto-chave destacado por Khatri et al. (2014) é o trabalho contínuo do grupo PhET na melhoria da qualidade das simulações e na forma de distribuição pela Internet. Desta maneira, a proposta do grupo PhET é continuar inovando com foco na "disseminação" e no "refinamento" das simulações.

Este trabalho é parte integrante de uma pesquisa de doutorado desenvolvida no Programa de Pós-Graduação em Ensino de Ciência e Tecnologia - Universidade Tecnológica Federal do Paraná, que investigou quatro hipóteses levantadas sobre o refinamento e a disseminação das simulações PhET. Neste artigo, é abordada uma das hipóteses, a qual envolveu um problema relacionado com a disseminação das simulações PhET.

O problema examinado na disseminação das simulações é em relação ao acesso às simulações interativas pelos estudantes em situações não formais de ensino, por exemplo, o acesso de casa ou no tempo livre. Este ponto é baseado em um relato do próprio grupo $\mathrm{PhET}$, descrito no portal em uma de sugestões e demandas de perguntas para serem pesquisadas ${ }^{2}$. Entre as perguntas de pesquisa sugeridas, encontra-se a seguinte questão: "Os alunos aprendem se eu lhes disser para ir para casa e usar uma simulação?".

Conforme o problema citado e o objetivo geral desta pesquisa, uma das hipóteses investigadas foi elaborada como segue: $\mathrm{H}_{1}$ : "A aplicação de game design nas simulações interativas do projeto PhET influencia de forma positiva o interesse dos estudantes pela utilização das simulações em situações fora do contexto escolar".

Este trabalho visa contribuir para a área de pesquisa em jogos digitais educacionais, a qual possui um interesse crescente no cenário brasileiro [RIBEIRO et al., 2015]. O resultado desta pesquisa pode contribuir com informações relevantes para a atividade de elaboração de propostas de game design, inclusive quando realizadas pelos próprios docentes. Por exemplo, em propostas de oficinas sobre game design para

\footnotetext{
2 Questões de interesse de pesquisa do grupo PhET. Disponível em: < https://phet.colorado.edu/pt_BR/research>. Acessado em: 10 de fevereiro de 2016.
} 
professores, conforme o relato de experiência de Araujo, Silve e Aranha (2016), que contou com a aplicação de oficinas sobre game design para 229 professores, 94\% mencionaram ter interesse pela área.

\section{Métodos}

Em pesquisas sobre jogos digitais educacionais, este estudo é classificado como pesquisa de valor agregado, conforme definições em Mayer (2014). Pesquisas de valor agregado buscam tanto contribuições práticas como contribuições teóricas para a área de Game Design Instrucional.

Dadas as características deste estudo, a abordagem metodológica adotada é categorizada como pesquisa de métodos quantitativos com coleta de dados de atitudes e dados observacionais, conforme orientações metodológicas em Creswell (2010). A análise dos dados observacionais é incorporada nessa pesquisa para corroborar com a análise dos dados quantitativos e, assim, complementar a interpretação dos resultados.

O procedimento metodológico foi aplicado com duas turmas de Ensino Médio com perfis semelhantes. Os 75 alunos participantes foram distribuídos aleatoriamente em um grupo experimental (grupo G) e grupo de controle (grupo S), a divisão em dois grupos foi realizada para verificar também outras três hipóteses, além da hipótese $\mathrm{H}_{1}$ abordada nesta pesquisa. $\mathrm{O}$ experimento envolveu a coleta de dados quantitativos e observacionais, neste relato, limita-se à análise e discussão dos instrumentos que envolvem a inferência da hipótese $\mathrm{H}_{1}$, citada na introdução, sendo: o registro de monitoramento de acessos às simulações utilizadas com os alunos após cada intervenção pedagógica e um questionário de levantamento do interesse dos alunos pela presença de uma seção de jogo incorporada às simulações de Física. $\mathrm{O}$ monitoramento dos acessos às simulações foi realizado com a utilização de um software comercial ${ }^{3}$ integrado ao portal Física Games ${ }^{4}$, criado no âmbito desta pesquisa.

Para investigar a hipótese $\mathrm{H}_{1}$, três aulas experimentais foram realizadas: a primeira utilizando a simulação Balançando, versão disponibilizada pelo grupo PhET; a segunda aula com uma versão modificada dessa mesma simulação, mas com a adição um elemento de game design sociointerativo; e a terceira aula com a simulação "Laboratório de Colisões", sem a presença de uma seção de jogo.

Exemplos de elementos de game design sociointerativos são: comunicação por texto ou voz entre jogadores (chat), modo multijogadores, placar de pontuação, registro e publicação de conquistas em painéis públicos, criação de perfis públicos (avatares), criação de grupos de amigos, opção de mercado para troca ou compra de itens entre jogadores, e outros.

\section{Resultados}

Durante a semana da realização da primeira aula experimental, em 20 de junho de 2016, com encerramento às $18 \mathrm{~h}$, foi realizada uma monitoria das visitas ao site de hospedagem

\footnotetext{
${ }^{3}$ Lucky Orange. Disponível em: http://www.luckyorange.com/. Acessado em: 7 de abril de 2016.

${ }^{4}$ Física Games. Disponível em: http://www.fisicagames.com.br/. Acessado em: 22 de agosto de 2017.
} 
das simulações e jogos. O objetivo do monitoramento foi avaliar o interesse espontâneo dos alunos em acessar os jogos fora do contexto escolar.

No mesmo dia da experiência, um dos alunos, participante do grupo $\mathrm{S}$, acessou o site às 21 horas e navegou por duas simulações do site: Monte um átomo e Aritmética. Este aluno permaneceu no site por 7 minutos e 20 segundos, durante este tempo, interagiu com duas simulações finalizando etapas em diferentes níveis de dificuldade. Após dois dias, este mesmo aluno retornou ao site para interagir novamente com a opção jogo da simulação Monte um átomo, durante 5 minutos. $\mathrm{O}$ aluno não acessou outras simulações nesta mesma sessão.

Um segundo aluno do mesmo grupo também acessou o site às $22 \mathrm{~h} 11 \mathrm{~min}$, mas não interagiu com as simulações ou jogos do site. Outros acessos não identificados também foram registrados durante a semana, porém, nestes casos, não foram observadas interações dos usuários com as simulações.

A segunda aula experimental foi realizada, no dia 4 de julho de 2016, com o mesmo simulador utilizado na aula anterior, mas com uma melhoria no design do jogo incorporado à simulação. $\mathrm{O}$ jogo recebeu a opção de placar de pontos com registro das maiores pontuações na própria página eletrônica da simulação. Este placar foi criado com a adição de um banco de dados MySql e scprits de acesso por PHP e programação Ajax, os quais foram incorporados à programação da simulação Balançando do projeto $\mathrm{PhET}$, a qual é programada com a linguagem Javascript. $\mathrm{O}$ placar online permitiu aos alunos registrarem e compartilharem as suas pontuações em diferentes níveis de dificuldades dos jogos presentes nas simulações PhET.

Após a aula, que encerrou às $18 \mathrm{~h}$ do dia 04 de julho de 2016, os acessos ao endereço eletrônico utilizado na aula foram monitorados. $\mathrm{O}$ primeiro acesso ocorreu no mesmo dia às 19:17 h, IP 187.xx.xxx.xx1, no qual um estudante entrou na mesma simulação da balança utilizada em aula e interagiu com a seção de jogo da simulação equilibrando as massas até atingir uma pontuação final no jogo. Esse acesso durou, aproximadamente, 2 minutos.

O segundo acesso, ainda no mesmo dia, ocorreu às 19:53 h, IP 201.xx.xxx.x9. Neste, o estudante primeiro acessou a página de placar geral das pontuações do jogo embutido na simulação Balançando, utilizado na aula. Após verificar o placar de pontuações, o estudante acessou o jogo da Balança e marcou pontos no nível 1 do jogo. Este acesso teve uma duração de 7 minutos.

No dia seguinte após a aula, 05 de julho de 2016, o terceiro acesso foi de um celular com sistema operacional Android. O estudante fez a entrada de seu celular com usuário e senha no sítio eletrônico às $12 \mathrm{~h} 32 \mathrm{~min}$. Primeiramente, o aluno acessou a página de placar geral do jogo da simulação Balançando e, depois, conferiu o placar geral de todos os demais jogos do sítio eletrônico. Então, o estudante acessou a simulação Balançando, não compatível com as telas de celulares, logo o aluno desconectou-se do site.

Outro acesso ocorreu ao sítio eletrônico, em 05 de julho de 2016, às 14h05min, pelo IP identificado foi um acesso da própria escola de um computador do laboratório de Informática. No caso, o acesso foi realizado por um estudante que estava em aula em uma disciplina da área técnica do seu curso. O estudante, primeiro, verificou o placar 
geral de pontuação e, depois, acessou o jogo da simulação "Balançando", interagindo com o jogo por, aproximadamente, 4 minutos.

$\mathrm{Na}$ mesma tarde, um acesso às $14 \mathrm{~h} 47 \mathrm{~min}$ foi realizado de um computador pessoal utilizado por um aluno utilizando a Internet da escola durante uma aula no laboratório de Informática. Este aluno interagiu por 4 minutos com o jogo Fatorar do sítio eletrônico e, depois, acessou o jogo da Balança. Durante a sessão, o estudante registrou suas pontuações no placar de pontuações online.

Ainda no dia seguinte após a aula, um acesso foi realizado por um estudante que entrou no sítio eletrônico com seu nome de usuário e senha às $19 \mathrm{~h} 11 \mathrm{~min}$, IP 138.xx.xx.xx3. Este aluno, primeiro, interagiu com o jogo da Balança por, aproximadamente, 5 minutos e, depois, acessou os demais jogos presentes no sítio eletrônico, totalizando um tempo de acesso de, aproximadamente, 15 minutos.

$\mathrm{Na}$ mesma noite, o próximo acesso foi realizado por outro estudante às 20h47min, o qual também interagiu com jogo da Balança, registrando 5 vezes a sua pontuação no placar de pontos online. No final, o estudante conferiu o placar de pontuação do jogo, finalizando o acesso com uma duração de, aproximadamente, 5 minutos.

No segundo dia após a aula, 06 de julho de 2016, um estudante entrou no sítio eletrônico às $14 \mathrm{~h} 09 \mathrm{~min}$, com seu nome de usuário e senha, de um computador da escola. Este aluno também acessou o placar geral e interagiu com o jogo da Balança por 4 minutos, registrando sua pontuação no placar online. Logo após, ocorreu outro acesso às 15h47min, no qual o usuário também verificou o placar geral e entrou no jogo da Balança.

À noite, ocorreu um acesso às $00 \mathrm{~h} 07 \mathrm{~min}$ do dia 07 de julho de 2016 , sendo realizado de um tablet com sistema operacional Android. Não houve interação com os jogos do sítio eletrônico neste acesso.

O próximo acesso ocorreu às $21 \mathrm{~h} 32 \mathrm{~min}$ por um aluno que entrou com nome de usuário e senha, IP 187.9x.xx.xx1. O acesso foi feito de um tablet, o qual tentou interagir com jogo da Balança, o acesso teve uma duração de, aproximadamente, 2 minutos. O mesmo estudante retornou ao sítio eletrônico utilizando um computador com sistema operacional Windows 8.1, desta vez, acessou o placar geral e interagiu com o jogo da Balança por, aproximadamente, 2 minutos.

Um estudante acessou o sítio eletrônico no dia 08 de julho de 2016, às 18h40min, IP 187.9x.xxx.x1, em um computador com sistema operacional Windows 10, o qual interagiu com as seguintes simulações, conforme ordem de acesso: Jogo de Multiplicar; Jogo de Dividir; Equações Químicas; Jogo de Fatorar; e Jogo dos Átomos. Este aluno registrou suas pontuações nos placares online dos seguintes jogos: Jogo de Dividir; Jogo de Fatorar; e Jogo de Multiplicação. O tempo de duração de acesso ao sítio eletrônico deste aluno foi de 1 hora e 7 minutos.

No dia 09 de julho de 2016 às $15 \mathrm{~h} 17 \mathrm{~min}$, outro estudante acessou o sítio eletrônico com seu nome de usuário e senha, IP 138.3x.xx.xx3, para verificar o placar geral, em acesso com duração de, aproximadamente, 1 minuto. 
Uma aluna acessou o sítio eletrônico com seu nome de usuário e senha no dia 10 de julho de 2016 às 20h34min, IP 187.9x.xxx.xx9, a qual interagiu com o jogo da Balança e conferiu o placar geral, em acesso com duração de, aproximadamente, 6 minutos. Esta aluna também fez o registro da sua pontuação no placar online do jogo da Balança. Nos dias seguintes, outros acessos ocorreram, inclusive com registros nos placares de pontuação dos jogos, porém, para o propósito desta pesquisa, foram considerados apenas os acessos no período de uma semana após cada aula.

Uma terceira aula experimental foi realizada no dia 28 de novembro de 2016 com os mesmos alunos das experiências anteriores. Esta experiência foi realizada em uma aula de Física sobre os conteúdos Colisão e Conservação da Quantidade de Movimento com a aplicação de uma simulação do grupo PhET no laboratório de Informática. Essa simulação não possui uma seção de jogo incorporada.

Após a aula, o sítio eletrônico teve seus acessos monitorados, novamente, para verificar o retorno espontâneo dos alunos. Neste caso, não houve registro de acesso dos estudantes. Isso aponta, novamente, que uma simulação sem uma seção de jogo não possui um design instrucional com efeitos motivacionais suficientes para atrair os estudantes em situações após a sua utilização em sala de aula.

Para saber a opinião dos alunos sobre a necessidade de jogo incorporado em simulação interativa, um questionário foi elaborado e aplicado após uma aula com o uso de uma simulação sem jogo incorporado, para verificar se alunos sentem ou não a falta de jogo na simulação. Nesta aula, o conteúdo da simulação utilizada foi "Laboratório de Colisões" e uma ficha de atividades foi entregue aos alunos com orientações e atividades sobre o tema.

O questionário de levantamento de interesse dos alunos pela seção de jogo é composto por 4 itens no formato de escala de Likert de 5 pontos: Concordo fortemente; Concordo; Sem opinião; Discordo; e Discordo fortemente. O questionário foi respondido por 71 alunos e os resultados obtidos estão representados no Gráfico 1.

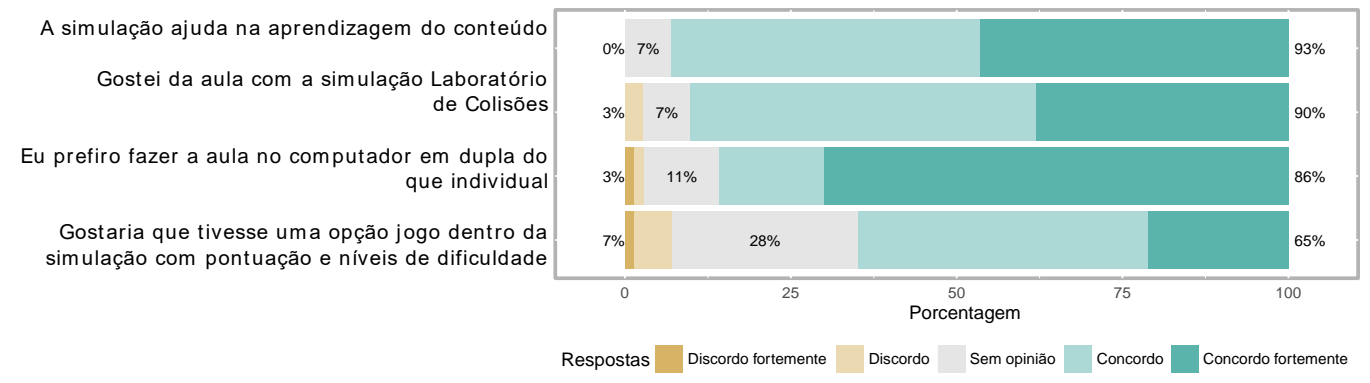

\section{Gráfico 1. Respostas do questionário aplicado em uma aula sem utilização de simulação com jogo incorporado.}

No Gráfico 1, destaca-se que apenas 7\% dos estudantes não gostariam de ter como opção uma seção de jogo em uma simulação do projeto PhET. Apenas 3\% dos estudantes preferem fazer a aula no computador de forma individual e não em dupla, a mesma percentagem de alunos não gostou da aula com a simulação "Laboratório de Colisões". Conforme os dados, $93 \%$ concorda com a capacidade da simulação em ajudar na aprendizagem do conteúdo. 
VI Congresso Brasileiro de Informática na Educação (CBIE 2017)

Anais do XXIII Workshop de Informática na Escola (WIE 2017)

\section{Discussão}

Esta pesquisa contou com o monitoramento dos acessos ao endereço eletrônico com as simulações utilizadas nas aulas experimentais. Após a primeira aula, apenas um aluno acessou o endereço de casa, interagindo somente com as seções de jogo disponíveis. $\mathrm{Na}$ segunda aula o jogo recebeu um aprimoramento com a adição de placar de pontuações, permitindo aos alunos registrarem seus resultados nos jogos presentes nas simulações. A opção de placar de pontuação acrescentou à simulação uma característica social, pois os alunos passaram a interagir com a simulação com o intuito de melhorarem seus resultados, tendo como referência os resultados obtidos por outros alunos.

Também foi observado que alguns alunos assumiram um comportamento mais competitivo, buscando melhorar sua pontuação no jogo para alcançar as posições mais altas dos placares de pontuação. Consequentemente, essa busca pela melhoria na pontuação exige que o aluno construa estratégias para solução de problemas que envolvem o conceito de momento de uma força, após um tempo, o aluno passa a aplicar estratégias de forma automatizada e esse conhecimento passa a compor, mais facilmente, a memória de longo prazo. Outra situação observada foi uma competição, que surgiu naturalmente entre as duas turmas participantes da pesquisa, pois, além do nome, os alunos passaram a registrar o nome do curso que frequentam.

No experimento, ficou evidente que, após a adição do placar de pontuação, houve um aumento significativo no interesse dos estudantes pelas simulações, considerando os 12 acessos, motivados pela seção de jogo e pela página com o placar de pontuação.

Posteriormente, foi realizada uma terceira aula experimental utilizando uma simulação sobre colisões, sem a presença de uma seção de jogo. Em um questionário aplicado no final da aula, $65 \%$ dos alunos responderam que gostariam que a simulação também tivesse uma seção de jogo embutida. Desses, $28 \%$ se posicionaram sem opinião e 7\% dos alunos marcaram que não tem interesse pela presença de uma seção de jogo embutida na simulação sobre colisões, conforme mostra o Gráfico 1.

Tanto os dados observacionais obtidos com o monitoramento dos acessos como os dados quantitativos evidenciam que a seção de jogo agrega valores às simulações, tornando-as mais atrativas, aumentando o número de retorno de acessos ao endereço eletrônico dos alunos em situações fora do contexto escolar.

Conforme os resultados aqui discutidos, as observações mostram que a simulação por si só não é suficiente para despertar o interesse geral dos alunos para retornarem ao sítio eletrônico, o que explica o baixo número de acesso dos alunos ao portal do projeto PhET fora do contexto escolar, atual preocupação dos desenvolvedores do portal. Como solução para este problema, uma alternativa é investir na melhoria do design da seção de jogo das simulações para torná-las mais sociointerativas, como exemplo, a melhoria realizada nesta pesquisa com a adição de placar de pontuações permitindo o registro dos nomes dos alunos em um ranking.

Essas observações corroboram com as discussões realizadas por Ellington, Addinall e Percival (1981), os quais já indicavam, na década de 1980, que a presença de competições em simulações ou jogos digitais é uma das razões para justificar o uso desses recursos no ensino de Ciências. As competições desafiam os alunos a se 
empenharem no jogo com maior motivação e interesse pela aprendizagem. Além do fator competição, os autores também já ressaltavam que os jogos interativos e multiusuários são capazes de auxiliar na socialização entre os alunos.

Essa influência na socialização dos alunos também foi observada nesta pesquisa, principalmente, durante as aulas com a simulação que recebeu a opção de placar geral de pontuação. Os alunos passaram a observar e conversar sobre as suas conquistas, conforme as pontuações eram registradas no placar geral de pontuação.

O interesse dos alunos pela seção de jogo presente nas simulações pode ser explicado por ser um fenômeno cultural, considerado por Huizinga (2000) como uma terceira função da vida humana, representada pela expressão Homo ludens (homem do jogo), enquanto que as outras funções são Homo faber e Homo sapiens. A função Homo ludens é natural à vida, inclusive ao nível animal. $\mathrm{O}$ jogo pode ser compreendido como resultado de uma descarga vital superabundante acompanhado de satisfação.

O jogo é uma atividade de prazer, assim, ao interagir com jogos digitais, os alunos se divertem enquanto aprendem [Cox e Bitterncourt 2017]. Esse sentimento de prazer está associado com a descarga de energia excessiva após um esforço, o qual deve ser voluntário. O jogo deve ser realizado com liberdade e apresentado como um convite para a brincadeira. A seção de jogo da simulação deve ser encarada como um anexo, uma atividade extra. Se utilizada em aulas, o professor deve deixar os alunos livres sem atrelar notas de rendimento escolar pela realização, ou não, dessa atividade.

Huizinga (2000) comenta que o jogo deve ser sempre praticado nas "horas de ócio" e foi assim que aconteceu com os alunos que acessaram o jogo de casa nos dias posteriores a aula. Não foi por necessidade física ou pelo dever moral, os alunos acessaram o jogo de casa por prazer e, em contrapartida, reforçaram a construção de esquemas úteis para a compreensão do conteúdo de Física envolvido na simulação.

A competição proporcionada pela seção de jogo da simulação também é compreendia por Huizinga (2000) como algo natural presente na formação da cultura, desde as sociedades primitivas. $\mathrm{O}$ interesse dos alunos em verificar constantemente $\mathrm{o}$ placar de pontuações está relacionado com o prazer que as pessoas têm em serem reconhecidas pelos espectadores de uma competição, além do comportamento de poder gabar-se a outros de seus êxitos, um caso de autoaprovação. Huizinga (2000) entende, nesses casos, que o "ganhar" é mais relevante quando há adversários, em grupo, o vencedor ganha estima, conquista e horarias.

Ao embutir uma seção de jogo na simulação, é importante que ela exija faculdades específicas e que os resultados não sejam, de maneira nenhuma, obtidos por pura sorte. Para Huizinga (2000), jogos de azar são inúteis para o estudo da evolução da cultura. $\mathrm{O}$ que não é o caso dos jogos presentes nas simulações PhET, esses exigem que os alunos apliquem estratégias de resolução de problemas associadas com conteúdos curriculares.

Outra abordagem, no âmbito da cultura contemporânea, para explicar o interesse dos alunos pela seção de jogos, é associar este comportamento com o mesmo que ocorre no fenômeno dos e-Sports, ou esportes eletrônicos, um novo gênero de entretenimento presente na sociedade [Kaytoue et al., 2012] [Américo 2014] [Pulcides e Nodari 2015]. 
Os e-Sports são, geralmente, compostos por jogos de estratégia ou de ação, e atingem um público mundial de jogadores e entusiastas. Entretanto, nesse cenário, também há espaço para os jogos digitais educacionais, como ocorre na Olimpíada de Jogos Digitais e Educação (OJE), na qual alunos de diferentes partes do Brasil participam de desafios com minijogos com conteúdos escolares que utilizam mecânicas de jogos clássicos [Meira e Pinheiro, 2012], [Meira, Neves e Ramalho, 2009].

\section{Conclusões}

Neste estudo, uma pesquisa de métodos quantitativos foi realizada para investigar e compreender dois problemas, atuais, observados nas simulações do projeto $\mathrm{PhET}$. O primeiro problema, abordado neste trabalho, é baseado em uma observação dos próprios pesquisadores do $\mathrm{PhET}$ ao relatarem que as simulações são pouco acessadas fora da escola pelos estudantes, com exceção quando estão integradas às tarefas de casa.

Diante do problema citado acima, essa etapa da pesquisa envolveu um delineamento experimental para investigar a relação entre a seção de jogo presente nas simulações PhET e o interesse dos estudantes em acessar a simulação por motivação direta. Para isso, uma plataforma foi utilizada para monitorar os retornos dos estudantes ao endereço eletrônico com as simulações após a sua utilização em uma aula de Física. Considerando a simulação com a seção de jogo em sua versão original, apenas um aluno acessou o endereço eletrônico e interagiu com as seções de jogos das simulações. $\mathrm{O}$ interesse desse aluno, em acessar espontaneamente o recurso, foi motivado pela seção de jogo, esta primeira coleta serviu de sondagem para a preparação de uma segunda etapa.

Em uma segunda etapa, a seção jogo da simulação foi aprimorada, com a implementação de um novo elemento de game design, um placar de pontuação para os alunos poderem registrar seus nomes e resultados obtidos nos diferentes níveis da seção de jogo da simulação Balançando. Após a aula com essa versão modificada, 12 acessos ocorreram no endereço eletrônico e observou-se que, nesses acessos, o interesse dos alunos foi pelas seções de jogos e pelos placares de pontuação. Essa atitude dos alunos está relacionada com a ideia de Homo ludens de Huizinga (2000), a terceira função da vida, considerada com um fenômeno cultural. Atualmente, o interesse dos jovens por competições com jogos eletrônicos também é evidente em eventos de e-Sports.

Como conclusão, sugere-se investir em melhorias na seção de jogo das simulações de código aberto do projeto PhET, adicionando elementos de game design sociointerativos, como uma alternativa para resolver o baixo número de acessos espontâneos dos estudantes em situações fora do contexto escolar.

\section{Referências}

Américo, M. O jornalismo esportivo transmídia no ecossistema dos esportes eletrônicos (E-Sports). Estudos em Jornalismo e Mídia, v. 11, n. 2, p. 316, out. 2014.

Araujo, G., Silva, T. R. e Aranha, E. A construção de jogos digitais na escola: um relato de experiência na formação de professores. Anais do Workshop de Informática na Escola, v. 22, n. 1, p. 161, 2016. 
VI Congresso Brasileiro de Informática na Educação (CBIE 2017)

Anais do XXIII Workshop de Informática na Escola (WIE 2017)

Cox, K. K., e Bittencourt, R. A. Estudo Bibliográfico sobre o Processo de Construção de Jogos Digitais: A Necessidade de Sinergia entre o Educar e o Divertir. Revista Brasileira de Informática na Educação, v. 25, n. 1, p. 16, 30 abr. 2017.

Creswell, J. W. Projeto de pesquisa: métodos qualitativo, quantitativo e misto. 3. ed. Porto Alegre: Artmed, 2010.

Ellington, H., Addinall, E. e Percival, F. Games and Simulations in Science Education. New York: Company, Nichols Publishing, 1981.

Huizinga, J. Homo Ludens. São Paulo: Editora Perspectiva S. A., 2000.

Kaytoue, M. et al. Watch me playing, i am a professional: a first study on video game live streaming. Proceedings of the 21st international conference companion on World Wide Web, p. 1181-1188, 2012.

Khatri, R. et al. Over One Hundred Million Simulations Delivered: A Case Study of the PhET Interactive Simulations. Physics Education Research Conference Proceedings, p. 205-208, 2014.

Mayer, R. E. Computer Games for Learning: An Evidence-Based Approach. Cambridge, MA: MIT Press, 2014.

Meira, L., Neves, A. e Ramalho, G. Lan House na escola: uma olimpíada de jogos digitais e educação. In: VIII Brazilian symposium on games and digital entertainment. Rio de Janeiro, RJ, 2009.

Meira, L. e Pinheiro, M. Inovação na Escola. Proceedings of SBGames 2012, p. 42-47, 2012.

Perkins, K et al. PhET: Interactive Simulations for Teaching and Learning Physics. The Physics Teacher, v. 44, n. 1, p. 18-23, 2006.

Pulcides, A. L. e Nodari, S. eSPORTS: narrativas em hipermídia como competições. Revista dito Feito, v. 6, n. 8, p. 1-13, 2015.

Ribeiro, R. J. et al. Teorias de Aprendizagem em Jogos Digitais Educacionais: um Panorama Brasileiro. Novas Tecnologias na Educação, v. 13, n. 1, p. 1-10, 2015. 